Article

\title{
WIND-STORM: A Decision Support System for the Strategic Management of Windthrow Crises by the Forest Community
}

\section{Simon Riguelle ${ }^{1,2, *}$, Jacques Hébert ${ }^{2}$ and Benoit Jourez ${ }^{1}$}

1 Laboratory of Wood Technology, Public Service of Wallonia, Avenue Maréchal Juin 23, Gembloux 5030, Belgium; E-Mails: jhebert@ulg.ac.be (J.H.); benoit.jourez@spw.wallonie.be (B.J.)

2 Unit of Forest Resources Management, Department Biosystem Engineering (BIOSE), University of Liège-Gembloux Agro-Bio Tech, Passage des Déportés 2, Gembloux 5030, Belgium

* Author to whom correspondence should be addressed; E-Mail: simon.riguelle@spw.wallonie.be; Tel.: +32-81-62-64-61.

Academic Editors: Jean-Claude Ruel and Eric J. Jokela

Received: 16 July 2015 / Accepted: 21 September 2015 / Published: 29 September 2015

\begin{abstract}
Storms are one of the most damaging agents for European forests and can cause huge and long-term economic impacts on the forest sector. Recent events and research haves contributed to a better understanding and management of destructive storms, but public authorities still lack appropriate decision-support tools for evaluating their strategic decisions in the aftermath of a storm. This paper presents a decision support system (DSS) that compares changes in the dynamics of the regional forest-based sector after storm events under various crisis management options. First, the development and implementation of a regional forest model is addressed; then, the potential application of the model-based DSS WIND-STORM is illustrated. The results of simulated scenarios reveal that this DSS type is useful for designing a cost-effective regional strategy for storm-damage management in the context of scarce public resources and that public strategies must encompass the whole forest-based sector to be efficient. Additional benefits of such a DSS is to bring together decision-makers and forest stakeholders for a common objective and therefore to enhance participatory approaches to crisis management.
\end{abstract}

Keywords: wind damage; crisis management; model; decision support system (DSS) 


\section{Introduction}

Wind storms are one of the most damaging agents for forests in the Northern Hemisphere, especially in Western Europe [1]. These natural disasters have significant social and environmental impacts [2] and inflict huge economic losses on the forest sector [3]. Impacts on the forest-based economy of exceptional events that blow down at least the annual average harvest at the industrial supply scale can last a couple of years [4]. Storms directly impact both timber production and timber prices [5], as forest owners are tempted to harvest to limit financial losses. This afflux of timber on the market combined with a poorer quality of fallen timber and the increasing costs of salvaging contribute to lower stumpage prices and inflict revenue losses on forest owners [6], who are also suffering from future revenue losses due to an anticipated harvest of non-mature stands [7]. The industry as a whole will also be affected, with the main impact being on roundwood prices and procurement in the mid to long term. After a storm event, there is a short-term increase in the wood supply, usually followed in the medium term by a supply shortage if no mitigation measures are taken [8]. A storm event will also cause operational difficulties resulting from the lack of harvesting and transport capacities (e.g., working force, harvesters, and trucks), which may slow windfall mobilization and storage operations.

These factors show how important it is that public authorities ensure post-storm crisis management to minimize the short-, mid-, and long-term economic, social, and environmental impacts on the forest-based sector. Public authorities such as governments and public bodies are the key players in the crisis management process for three main reasons: first, they act at the legislative and decisional levels to facilitate or promote crisis measures; second, they can mobilize financial resources to support the forest-based sector; finally, they are the central point of contact for forest-based sector stakeholders. Given current scarce public resources; however, their first priority is adopting the most efficient crisis measures to provide return on public investments. Given the strong interrelation among actors in the forest-based sector, they must not only consider the measures' efficiency on an individual basis but also pursue the global improvement of the system. These tasks require setting up support tools in order to improve strategic decision-making.

One general way to support decision-making is to use models included in decision support systems (DSSs) to make them more accessible to end-users. Most of the DSSs used in forest management are model-based [9,10]. Models are also frequently used in forest economics to simulate situations that may result from changes in policy (e.g., new subsidies, tax systems), market conditions [11], or climatic conditions [12]. Among these models, some are general equilibrium models, in which the forest sector interacts with other sectors of the economy [13,14]. Models in which only the forest sector is analyzed, ignoring interactions with other economic sectors, are considered partial equilibrium models. The model scope may vary, from local to international scale - the latter including the interrelations among national forest sectors. For example, the Global Forest Products Model (GFPM) described by Buongiorno, et al. [15] can be used to simulate how timber production and the harvesting, manufacturing and transportation of products in various countries interact through international trade. Model applications to forest-wood chain management are various: they include demand and procurement [16], harvest planning [17], productivity of harvesting operations [18,19], and transportation planning [20-22]. Models are also frequently used in operational research to support industry and organizations in forest-wood chain planning [23-26], after the storm Gudrun in Sweden 
for instance [27]. However, no DSS has been proposed to support systemic analysis and strategic management of storm damage and associated impacts on the forest-based sector after storm events.

Therefore, this paper presents an original DSS to assist post-storm crisis management and support public authorities' decision-making in the aftermath of huge storms. The DSS' expected output is a comparison of changes in the dynamics of the regional forest-based sector after storms under different crisis management options. The DSS is based on a regional forest model (WALFORM) developed for a case study of Wallonia, the southern region of Belgium. The first chapter describes the development, implementation, and calibration of the model. The second presents an application of the model-based DSS WIND-STORM to a hypothetical storm crisis. Finally, a discussion and conclusions highlight the pros and cons of using this DSS for storm crisis management.

\section{The Regional Forest Model (WALFORM)}

\subsection{Conceptualization}

This model represents the regional forest-wood chain dynamics after a storm event. The system dynamics is modelled in terms of stocks, representing the state of the system at any given moment after the storm, and flows, representing the rate at which these stocks are changing at any given instant. System dynamics [28] has been used to model the interactions between stocks and flows, as this quantitative modeling method enables the building of a simple representation of complex systems. It has been used in several studies on forestry [29-33] and supply chain management [34]. To identify the stocks, the regional forest-wood chain is considered to be the succession of several forest operations: wood purchase, harvesting operations in the forest stands, the transportation of logs and bolts outside forest areas (either to industry sites or to storage terminals), and their primary transformation by local industries for various uses (e.g., sawn timber, paper, panels, fuel wood).

Figure 1 presents a conceptual representation of WALFORM in terms of stocks and flows. The model consists of four interrelated subsystems: purchase, harvesting, transport (including storage), and industry modules. A distinction is made between windfalls, trees affected by wind damage (e.g., uprooted or broken trees), and timber, trees unaffected by the storm (either standing trees or wood products derived from them). For any moment $t$, input and output rates (flows) determine the level of windfalls and timber within each module (stocks). The rates correspond to the financial or technical capacities available to purchase, harvest, transport, store, or process windfalls and timber. Four groups are distinguished in the model, both for windfalls and timber (spruce, other softwoods, beech, and other hardwoods). For the industry module, groups of species are aggregated in two raw material types (softwood and hardwood species).

The first step in building the model was selecting the parameters that influence the stocks and flows in a normal situation (i.e., no storm damage); then, the parameters specific to windthrow crises were added. This selection occurred in close collaboration with stakeholders from the forest-based sector, using expert knowledge to sort the information. Particularly challenging was finding a way to reflect the range of storm damage management options implemented in the past, in both Belgium and elsewhere. Figure 2 presents the WALFORM model derived from the previous conceptual representation using System Dynamics generic notations. Boxes represent stocks; hourglasses with 
double arrows represent flows (in italic and bold), and all other elements are converters. The model is composed of 13 stocks, 18 flows, and 61 converters (either constant or variable), as listed and described in Table S1. The simple arrows in Figure 2 represent the interactions between parameters. Blue arrows indicate a positive influence: the higher the initial converter is, the higher the impacted converter will be. Red arrows indicate a negative influence: the higher the initial converter is, the lower the impacted converter will be. Dashed arrows indicate that the converter determines only the initial value of a stock. Black arrows with delay marks indicate that a time delay may be applied to the targeted converter. For instance, the activation of payment delays (delay pay) may block or lower the associated converter (timb to pay) for a pre-determined period.

The WALFORM model is an open system: unlike feedback systems, it is not influenced by its past behavior. The capacities (flows) are the only parameters that determine stock levels. However, the levels of stocks downstream from the system are a function of the upstream stocks; thus, the real value of flows will be the minimum between the capacities and the amount of wood (windfalls or timber) available in the stocks at that time. The mathematical relations between stocks and flows and between flows and converters are presented in Table S2. Euler integration is used to solve the equations. Due to the complexity of these relationships, the sections below will focus on the converters of the four modules and their positive or negative influence on the capacities.

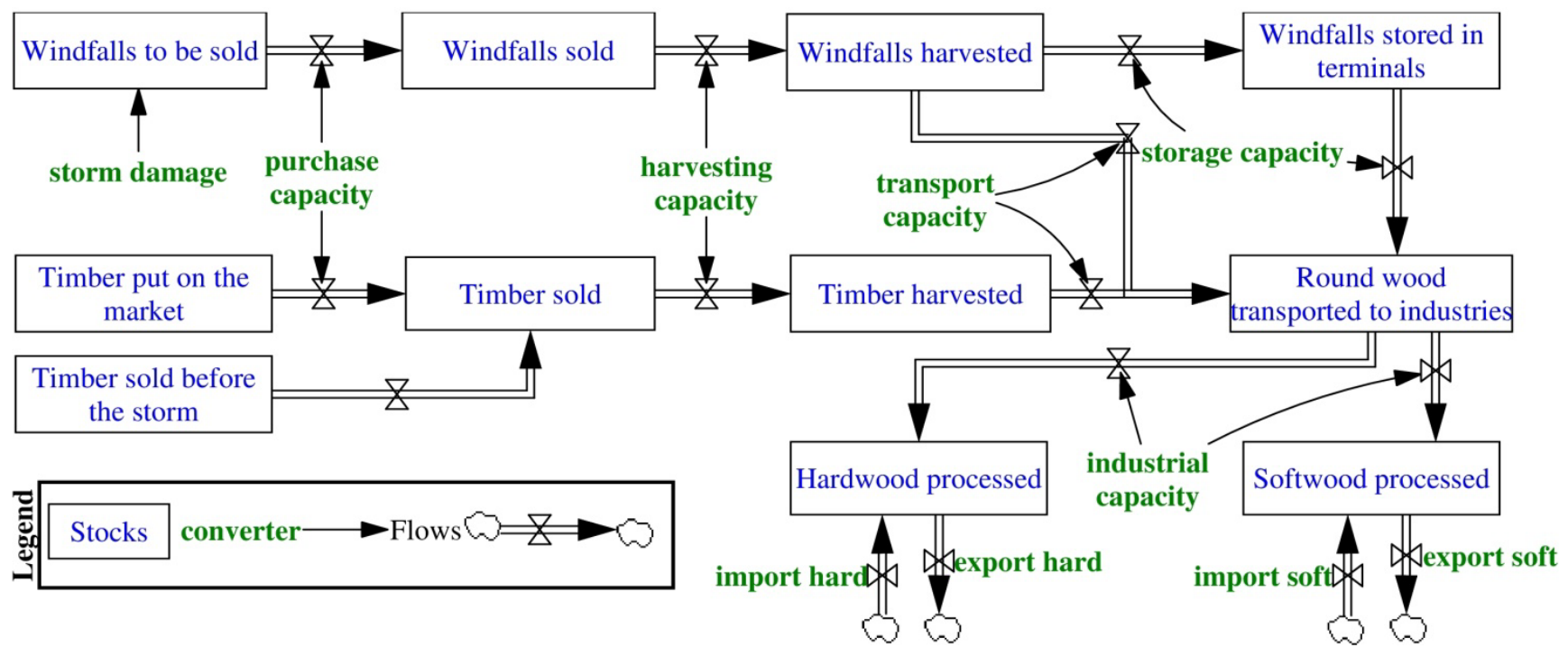

Figure 1. Conceptual representation of the regional forest-wood chain. 


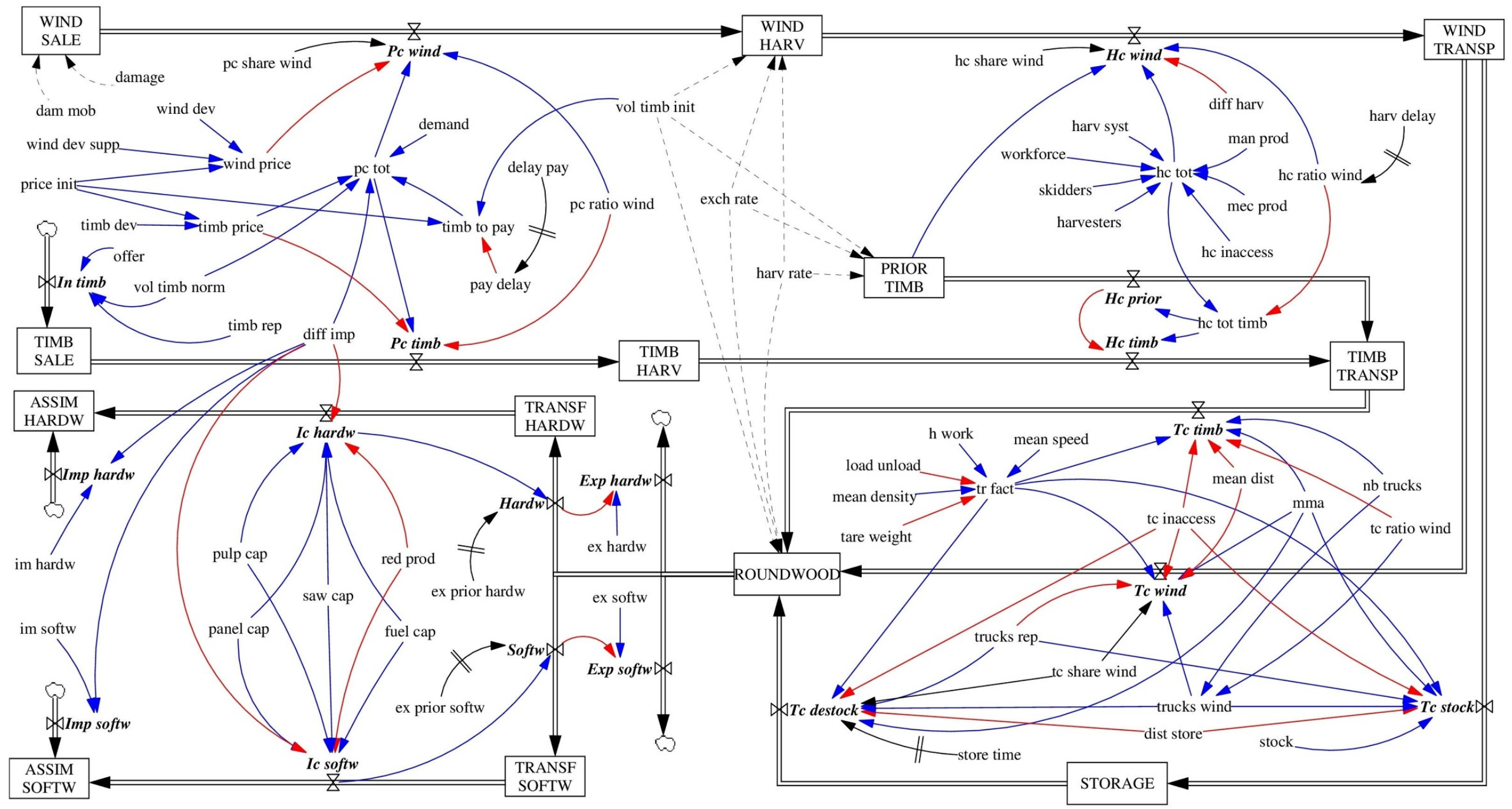

Figure 2. WALFORM model structure and parameters. Boxes represent stocks, double arrows with hourglasses flows (in italic and bold). Blue (red) arrows indicate a positive (negative) influence between converters. Dashed arrows indicate that the converter determines only the initial value of a stock. Black arrows with delay marks indicate that a time delay may be applied to the targeted converter. 


\subsection{Purchase Module}

The purchase module (see Figure 3 ) depicts the dynamics of windfalls and timber sales. The two main inputs are the volume of damage and the standing timber put on the market. The amount of windfalls to be sold (WIND SALE) depends on the initial amount of the damage (damage) and the damage mobilization rate (dam mob), which reflects the proportion of windfalls inaccessible or economically unprofitable to harvest. In the case study on Wallonia, a quick damage assessment methodology enables an estimation of the amount of damage within $72 \mathrm{~h}$ to feed the model [35]. The amount of timber put on the market (TIMB SALE) is a function of the annual repartition of sales (timb rep), of the average annual sales (vol timb norm), and of supply variation (offer). The offer parameter reflects the willingness to put more or less timber on the market during the crisis period. It must be defined for each group of species and for separate periods of 12 months. It is an aggregated value, meaning that it reflects the average behavior of public and private owners.

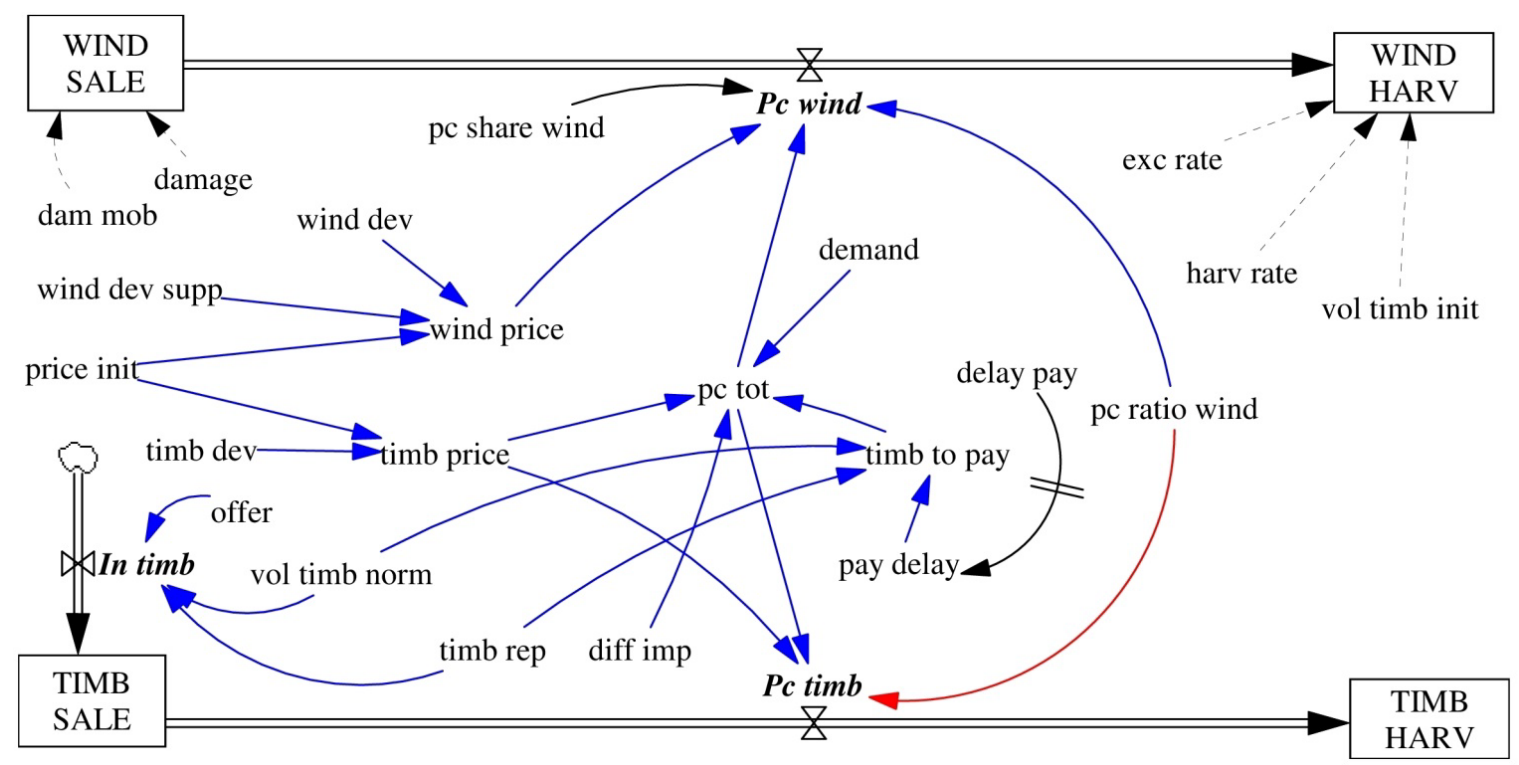

Figure 3. Purchase module.

The purchase capacity (pc tot) is the global financial capacity for buying wood, expressed in monetary terms. It is affected mainly by prices and demand (see Table S2 for mathematical relations). Prices after the storm are obtained by applying a devaluation rate (wind dev, timb dev) to the initial prices (price init), which are stumpage prices' mean current value for each group of species, obtained through statistical methods [36]. Additional devaluation may be applied to windfalls from the second year (wind dev supp). The purchase capacity assigned to windfalls ( $P c$ wind) and timber $(P c$ timb) is chosen by the user (pc ratio). The government may exceptionally authorize a deferred payment plan for a limited period in order to temporarily boost purchase capacity (pay delay); here, potential buyers benefit from higher financial capacities in the early months and are allowed to pay off the balance later. Increases and decreases in roundwood demand under economic constraints are also taken into account (demand). In the model, variations among imports (diff imp) directly affect purchase capacity, as reduced (increased) imports are thought to be compensated for by a higher (lower) demand for local resources. Regardless of purchase capacity, public authorities may foster exchanges between timber 
already bought and windfalls in order to redirect prior investments. This proportion will depend on the predetermined exchange rate (exch rate) and on the amount of timber sold before the storm (vol timb init) and not yet harvested.

\subsection{Harvesting Module}

The harvesting module (see Figure 4) focuses on the harvesting operations within the forest-wood chain. Upstream stocks are amounts of wood sold that must be harvested; downstream stocks are amounts of wood harvested that must be transporter to either storage terminals or industrial sites. The volume to harvest in forest areas is still divided between windfalls and standing timber at this stage, as harvesting systems and productivity differ in both cases. The module also includes the amount of windfalls exchanged with timber and the timber sold before the storm (PRIOR TIMB). Again, public authorities may extend harvesting delays (harv delay) for a limited period to increase the windfalls harvesting rate.

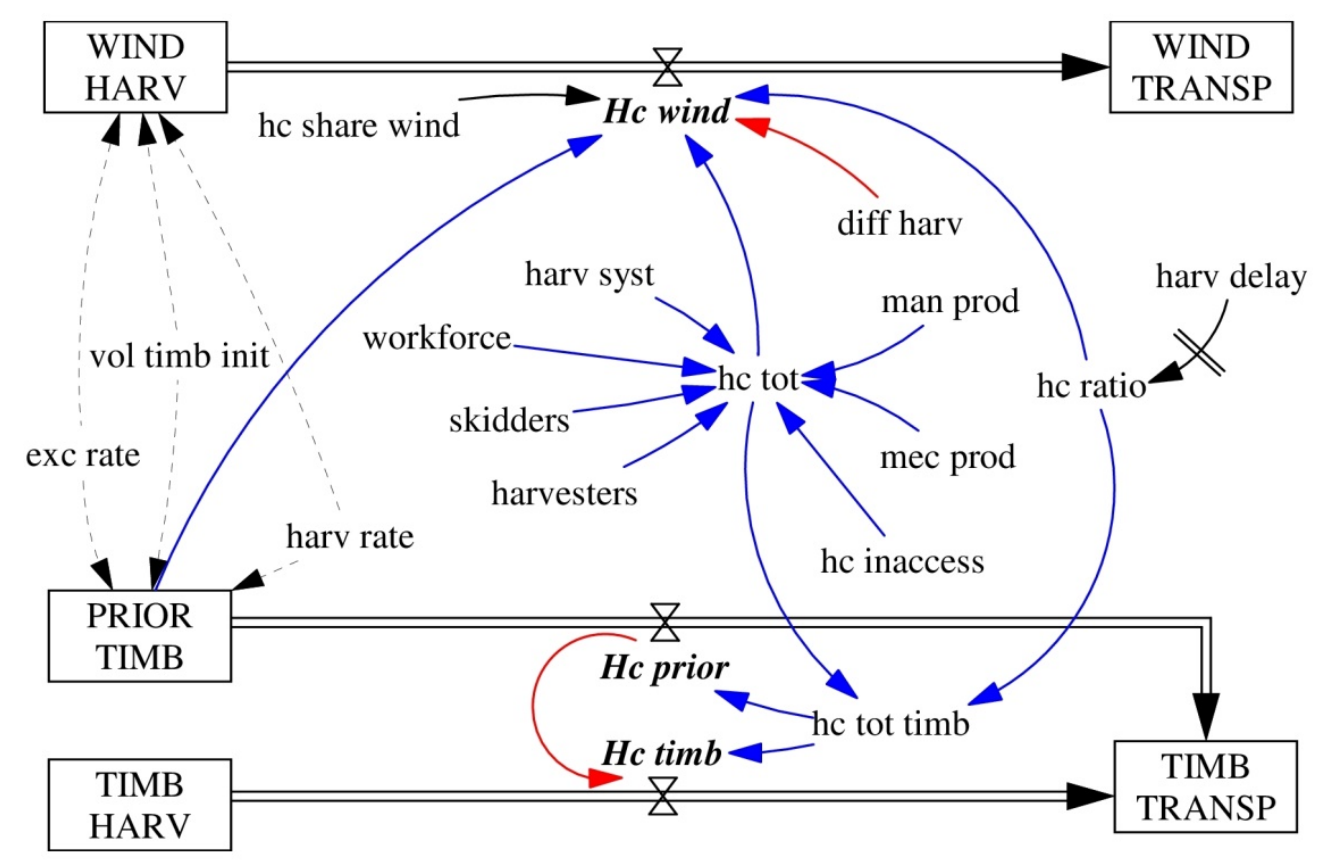

Figure 4. Harvesting module.

Harvesting capacities relative to windfalls $(H c$ wind $)$ and timber $(H c$ timb) are derived from the total harvesting capacity (hc tot). The overall capacity is a combination of several parameters: the available working force (workforce) and harvesters (harvesters), the manual and mechanical harvest productivity (mec prod, man prod), and the choice of harvesting systems (harv syst). For example, in damaged stands, mix harvesting systems are frequently required to ease access through entwined trees. This global capacity is pooled and redistributed according to strategic choices (hc ratio). For windfalls, a reducing factor (diff harv) is applied to reflect the more difficult working conditions and the lower productivity in damaged areas. As in the purchase module, a specific distribution of harvesting capacity between each group of species may be simulated (hc share wind). For example, priority may be placed on harvesting the species with a lower natural durability first to prevent them from decaying. 


\subsection{Transport Module}

The transport module (see Figure 5), focusing on the transportation of wood from forest areas to industrial sites or storage terminals, is a highly strategic link in the forest-wood chain. In this module, windfalls are again distinguished from timber products, under the hypothesis that there are no economic reasons to store undamaged timber on storage sites. However, the level of roundwood stock is the sum of windfalls and timber volumes brought to industrial sites. If storage is activated, the maximal amount to store (stock) and the minimal storage time (store time) must be defined. Transport from storage locations to industries will not be possible if the minimal storage time is not reached. Nevertheless, storage is an option and can be bypassed in the model.

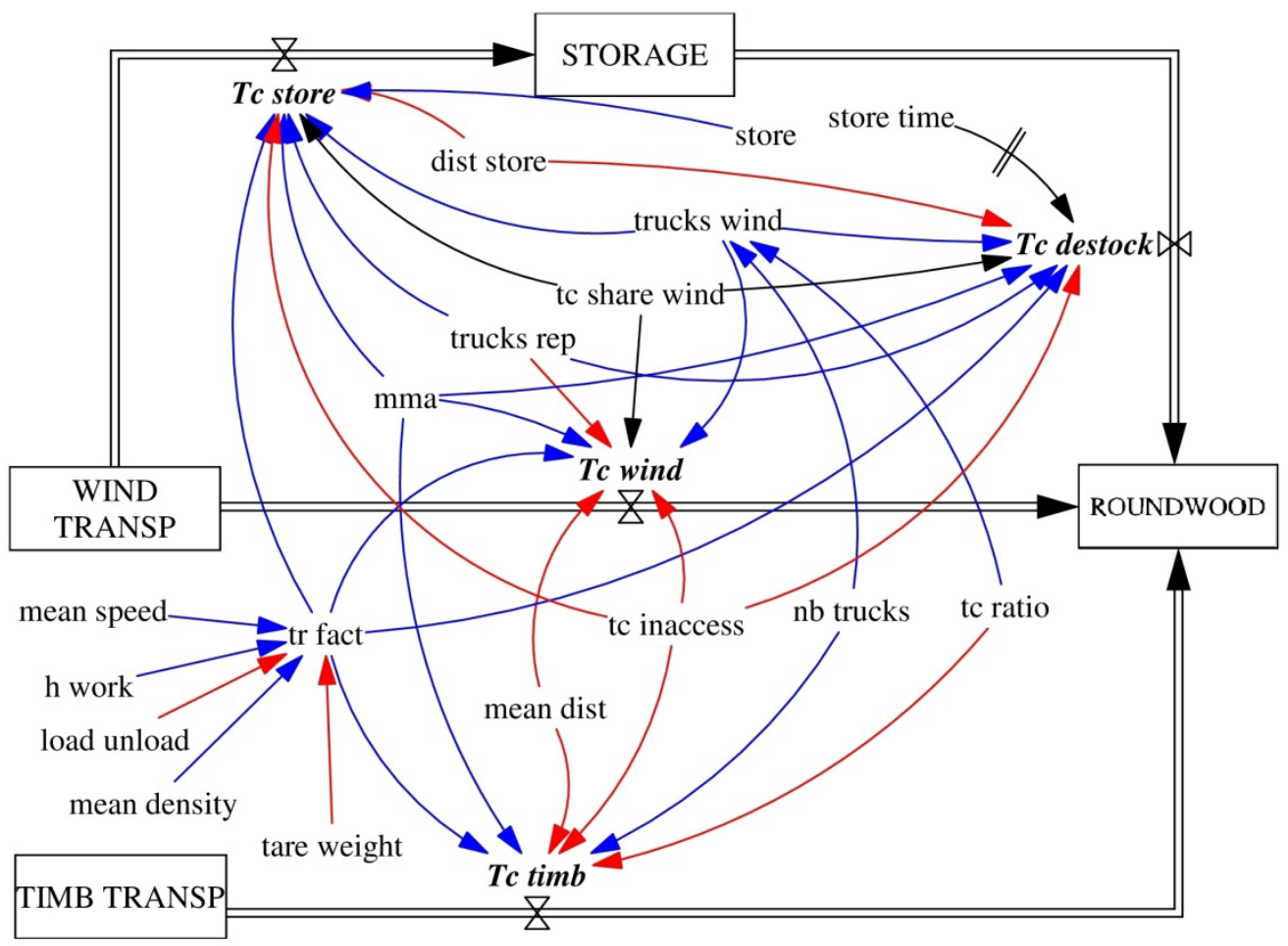

Figure 5. Transport module.

The specific transport capacities (Tc wind, Tc timb, Tc store, Tc destock) are functions of several parameters: the number of trucks, the maximum mass authorized for the trucks (mma), the mean distance of transport from either forests to industries (mean dist) or forests to storage terminals (dist store), and the truck productivity factor (tr fact). The quantity of trucks available for each operation is predetermined by the user. All of these parameters must be determined for both normal and crisis situations, as specific authorizations may be delivered for limited periods to boost the transport capacity (e.g., to increase the maximum mass authorized for trucks or public incentives to resort to foreign haulers).

\subsection{Industry Module}

The industry module (see Figure 6) represents wood consumption by the primary timber industries (sawmills, paper mills, wood panel manufactures) and the fuel wood sector. In this step, the groups of 
species are aggregated into two types of raw material: softwood (including spruce and other softwood species) and hardwood (beech and other hardwood species). Exporting flows (Exp hardw, Exp softw) drain roundwood out of the system, while importation flows (Imp hardw, Imp softw) add volumes at the end of the process. Industrial capacities for hardwood (Ic hardw) and softwood (Ic softw) are obtained from specific sector capacities (saw cap, pulp cap, paper cap, fuel cap).

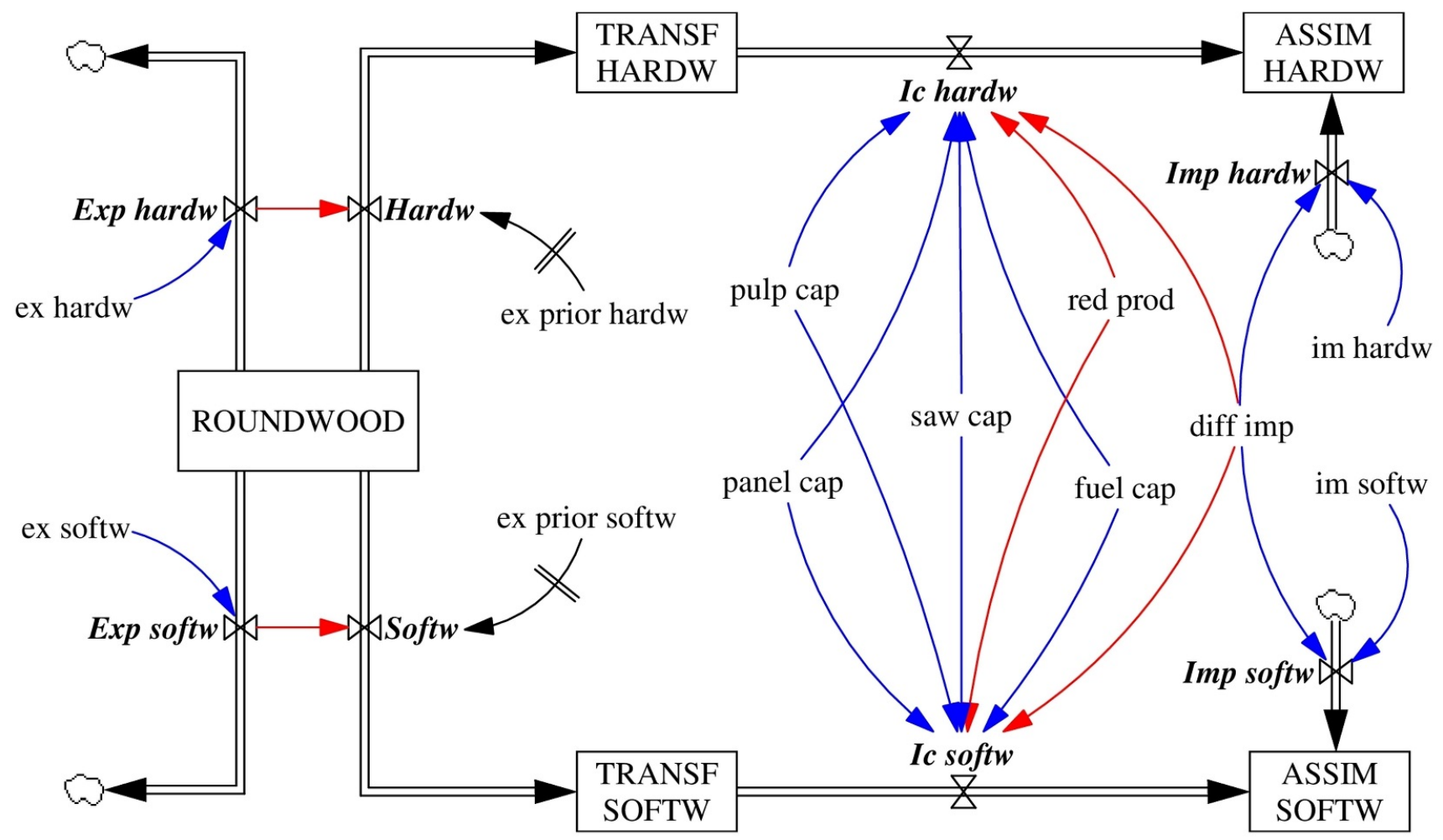

Figure 6. Industry module.

\subsection{Implementation and Calibration}

The model was implemented in Excel VBA (Visual Basic for Application 6.3). Excel software seems an appropriate trade-off among accessibility to a wide public, the possibility of designing user interfaces, the power of calculation, and programming interface. The model simulates a 60-month period after a storm event, with a time step of one month. It was calibrated for the regional forest-based sector of Wallonia with data collected through an intensive literature review and interviews with stakeholders. Given normal market conditions, without storm damage, a high degree of agreement between simulated and observed data has been obtained using expert knowledge. For some aspects of storm damage management, comparisons using annual statistics for the forest-based sector were made to validate the model. Feedbacks from previous storm crises in other regions also provided data specific to windthrow crises that could be used after verification. Unfortunately, no complete historical data were available in Belgium with which to validate entirely the model integrating storm damage by comparing its behavior to real crisis dynamics. Nevertheless, the match between model results and real system behavior after a storm was verified via expert knowledge. 


\subsection{Sensitivity Analysis}

As mentioned, the model is not intended to give a precise stock value but to compare crisis management scenarios (in a "what-if" analysis). Due to the model's limited validation process, however, it was essential to determine the optimal level of precision needed when gathering data and assess model robustness through the relative influence of parameters varying over a certain range on the end result [37]. To this end, sensitivity analyses were carried on in each module and on all parameters. A selection of studied parameters is presented in Table 1. For each selected parameter, the calibration value that gave the best fit between the simulated and real world was changed by $\pm 10 \%$ increments while the other variables were left unchanged. Differences up to $15 \%$ between extreme values were considered significant [38]. For converters with values that are functions of several variables, we first calculated the impact of a $\pm 10 \%$ change on the initial value and then assessed how the error spread over the simulation period.

Table 1. Effect on model indicator of increasing or decreasing the selected parameters by $10 \%$. Results express the difference from the reference state. The sign (-) reveals an under-estimation. Figures in bold indicate a significant difference (over 15\%) between extreme values.

\begin{tabular}{|c|c|c|c|c|}
\hline Parameter & Module & Indicator & $-10 \%$ & $+10 \%$ \\
\hline \multirow{2}{*}{ price init } & \multirow{2}{*}{ Purchase } & Time to sell all windfalls & - & - \\
\hline & & Unsold timber after 60 months & - & - \\
\hline \multirow{2}{*}{ wind dev } & \multirow{2}{*}{ Purchase } & Time to sell all windfalls & $-20 \%$ & $7.7 \%$ \\
\hline & & Unsold timber after 60 months & $-14 \%$ & $11.5 \%$ \\
\hline \multirow{2}{*}{ demand } & \multirow{2}{*}{ Purchase } & Time to sell all windfalls & $-4 \%$ & $4 \%$ \\
\hline & & Unsold timber after 60 months & $40 \%$ & $-48 \%$ \\
\hline \multirow{2}{*}{ offer } & \multirow{2}{*}{ Purchase } & Time to sell all windfalls & - & - \\
\hline & & Unsold timber after 60 months & $-44 \%$ & $44 \%$ \\
\hline \multirow{3}{*}{ harvesters } & \multirow{3}{*}{ Harvesting } & Total harvesting capacity & $-8 \%$ & $8 \%$ \\
\hline & & Windfalls harvested & $-8.7 \%$ & $7.9 \%$ \\
\hline & & Total volume harvested & $-7.7 \%$ & $6.8 \%$ \\
\hline mec prod & Harvesting & Total harvesting capacity & $-8 \%$ & $8 \%$ \\
\hline workforce & Harvesting & Total harvesting capacity & $-2 \%$ & $2 \%$ \\
\hline man prod & Harvesting & Total harvesting capacity & $-2 \%$ & $2 \%$ \\
\hline dist store & Transport & Time to store & $-4 \%$ & $4 \%$ \\
\hline tr fact & Transport & Round wood transported to industry & $-7.8 \%$ & $7.8 \%$ \\
\hline $\mathrm{nb}$ trucks & Transport & Round wood transported to industry & $-8 \%$ & $7.8 \%$ \\
\hline im hardw & Industry & Local hardwood processed & $-1.2 \%$ & $1.2 \%$ \\
\hline ex hardw & Industry & Local hardwood processed & $8 \%$ & - \\
\hline
\end{tabular}

Price init; stumpage prices before the storm; wind dev: devaluation of windfalls stumpage prices (first year); demand: demand for timber; offer: timber put on the market; harvesters: number of harvesters; mec prod: the mechanized harvest productivity; workforce: number of fellers; man prod: the manual harvest productivity; dist store: the mean distance of forests to storage terminals; tr fact: the truck productivity factor; nb trucks: total number of trucks available; im hardw: hardwood importation; ex hardw: hardwood exportation. 
Sensitivity analysis results show that estimated stumpage prices have no influence on the system stocks but influence only the cash flow between owners and merchants and the total value of sales. Contrariwise, the devaluation rate applied to windfalls may have a significant impact on the amount of sales: the higher the devaluation, the faster the sales of windfalls, but the relation appears not to be linear. Changes in demand and offer do not influence the time required to sell windfalls but have huge impacts on the stock of unsold timber after 60 months. Thus, if decision-makers focus only on windfalls mobilization, those parameters are not crucial; when considering the impacts on forest owners, however, they should be determined carefully.

In the harvesting module, the impacts of $\pm 10 \%$ variation are less obvious. The impacts of changing mechanical harvesting capacity (i.e., number of harvesters or productivity) on the total harvesting capacity may be explained by the greater contribution of mechanical harvesting relative to that of manual harvesting. On the other hand, errors in the estimation of manual harvesting capacity (i.e., number of fellers or productivity) have a marginal impact on total harvesting capacity. In the transport module, changes of $\pm 10 \%$ in the average distance between forest areas and storage terminals do not significantly impact the time needed to store windfalls. This result does not indicate that this distance is optimal (see below), but it does reveal that error in its estimation has no influence on the model. Conversely, variations in transport capacity (i.e., number of trucks or productivity) influence the total amount of roundwood transported to industries.

As mentioned, the sensitivity analysis results are also useful for evaluating which parameters are main influences on the stocks and fluxes of the system. For instance, if their influence were strong, decision-makers would know that those parameters might be key levers of the system when using the DSS based on the model (see section below). The exercise was made for the average distance between forest areas and the storage terminals parameter (dist store). Starting from a reference of $30 \mathrm{~km}$, the sensitivity analysis showed no significant impact of a $10 \%$ decrease or increase (see Table 1). However, when larger or smaller distances were taken into account (i.e., 10, 20, 40, $50 \mathrm{~km}$ ), the time required to store the targeted amount of windfalls varied between $-17 \%(10 \mathrm{~km})$ and $+20 \%(50 \mathrm{~km})$. The mean distance between storage places and forest areas thus appears to be a key element of wood storage policy after a storm. Such thorough analysis should be used to improve forest-wood chain functioning before the next storm, with the limitation that the state of the system is constituted by the dynamic combination of 61 converters and 18 flows; thus, merely optimizing each individual parameter will not lead to the perfect scenario for all stakeholders.

\section{Model Application: The WIND-STORM Decision Support System}

\subsection{The Decision Support System}

A DSS named "WIND-STORM" (Wind Damage Strategic Tool for Risk Management) was developed on the basis of the WALFORM model in order to provide a multitasking tool for supporting strategic decision-making. WIND-STORM was built to support three kinds of objectives: (1) to compare crisis management scenarios in the aftermath of storms in order to select the best management scenario for the whole forest-based sector; (2) to identify the main bottlenecks in the wood mobilization chain for the chosen scenario in order to solve them; and (3) to run prospective analyses 
on the system outside crisis periods to apply structural solutions to specific issues. The first two uses of the DSS rely on real data and market conditions corresponding to the month in which the windstorm strikes, while prospective analyses are based on estimated parameter values derived from the normal functioning of the regional forest-based sector. The software is linked to an online storm damage assessment application that supplies input data for simulations [35]. In addition, an associated graphical module (Excel spreadsheets) allows visual representation and a comparison among simulations.

\subsection{Case Study}

Value added of this DSS for storm crisis management is assessed below through a comparison between four crisis management scenarios (SC1 to SC4) and a business-as-usual (BAU) situation (in which authorities take no action after the storm). For a hypothetical storm occurring in January 2015, scenarios based on an overall estimated damage of $8 \times 10^{6} \mathrm{~m}^{3}$, an average $40 \%$ decrease in windfall stumpage prices and a $10 \%$ reduction in the demand for local resources were run. The damage is split as follows: $70 \%$ for spruce and 10\% for the other 3 groups of species. A $25 \%$ reduction in harvesting productivity in damaged areas is applied. Table 2 presents a selection of the parameters that were alternatively changed in the crisis scenarios to evaluate their effect. It is important to note that this selection is only one case study among a wide range of possibilities. In a real crisis context, technical and financial constraints will reduce the initial array of scenarios. In the BAU scenario, all parameters were set at their initial (calibration) values, except for those specifically related to windfalls purchasing, harvesting, and transport capacities, which were set to $50 \%$.

Table 2. Selected parameters for business-as-usual (BAU) and crisis scenarios (SC1 to SC4).

\begin{tabular}{cccccc}
\hline Parameters & BAU & SC1 & SC2 & SC3 & SC4 \\
\hline P 1. Exchange rate (\%) & 0 & 0 & 10 & 10 & 20 \\
P 2. Purchase capacity dedicated to windfalls (\%) & 50 & 50 & 66 & 66 & 66 \\
P 3. Offer shift & - & - & $a$ & $b$ & $c$ \\
P 4. Payment delays (years and \%) & - & $1 \%-50 \%$ & - & $1 \%-50 \%$ & - \\
H 5. Number of fellers (workforce) & 105 & 125 & 136 & 136 & 136 \\
H 6. Number of harvesters & 105 & 125 & 136 & 136 & 136 \\
H 8. Harvesting delays (months) & 50 & 66 & 66 & 75 & 85 \\
T 9. Trucks & - & - & - & 18 & - \\
T 10. Maximal weight (T) & 150 & 150 & 150 & 150 & 175 \\
T 12. Storage (Mm ${ }^{3}$ ) & 44 & 44 & 55 & 55 & 55 \\
T 11. Transport capacity dedicated to windfalls (\%) & 50 & 66 & 66 & 66 & 75 \\
T 13. Minimum storage time (months) & - & - & - & 1,2 & 1,6 \\
T 14. Truck repartition (\% for storage) & - & - & - & 12 & 24 \\
I 15. Importations shift hardwood (Mm ${ }^{3} /$ year) & - & $-10 \%$ & - & - & - \\
I 16. Importations shift softwood (Mm ${ }^{3} /$ year) & - & $-10 \%$ & - & - & - \\
I 17. Priority to export SW (Yes/No) & Yes & No & Yes & Yes & Yes \\
\hline
\end{tabular}

For each crisis scenario, we investigated the effects of several policies or supporting measures on post-storm operations, assuming that the selected parameters were among the most relevant for storm 
damage management. For the purchase module, several values for exchange rate (see parameter P1 in Table 2), purchase capacity dedicated to windfalls (P2) and offer shift (P3), as well as the activation of payment delays (P4) are evaluated. For harvesting operations, the number of fellers (H5) and harvesters (H6) available for work are modulated in the crisis scenario. The variation in harvesting capacity dedicated to windfalls (H7) and the application of delays in harvesting pre-sold timber (H8) are also tested. For the transport module, the study focuses on the number of trucks (T9), the maximum authorized weight of the trucks (T10), and the shift in transport capacity dedicated to windfalls (T11). The impact of wood storage is tested through the stored amount and the minimum storage period (T12 and T13). Finally, for the industry module, a 10\% drop in softwood and hardwood imports (I15 and I16) and a restriction on hardwood species export (I17) are simulated.

\subsection{Results}

The charts in the embedded graphical module cover a broad range of indicators for the four subsystems and provide a comparative perspective for decision-making. The WIND-STORM software can also provide more detailed information for decision-makers, such as economic losses for owners, storage costs, or commercial trade balance (exports minus imports). This section presents a brief overview of the potential outputs of the DSS for the five selected scenarios and their interpretation in terms of crisis management. Readers will be able to full feature of DSS outputs it will soon be freely available. The considerations below are valid only for this specific case study. Results will be discussed for each module first and then from a systemic point of view.

Figure 7A shows that, without specific measures, about 28 months are needed to sell the entire amount of windfalls in the BAU scenario. An increase in the purchase capacity dedicated to windfalls from $50 \%$ to $66 \%$ can reduce this length by around 8 months. The length of the sale period is not really affected by payment delays ( $\mathrm{SC} 1$ and $\mathrm{SC} 3$ ), but this measure helps to sell more windfalls in the first year following the storm. Figure 7B illustrates that the excess supply reaches over $6 \times 10^{6} \mathrm{~m}^{3}$ without any action (BAU scenario) and tends to balance at around $5 \times 10^{6} \mathrm{~m}^{3}$ for SC1 and SC2, more than an average annual harvest $\left(4 \times 10^{6} \mathrm{~m}^{3}\right)$. Only a huge reduction in supply, by half the usual amount over the simulation period, leads to a balanced system (SC4) after 60 months.
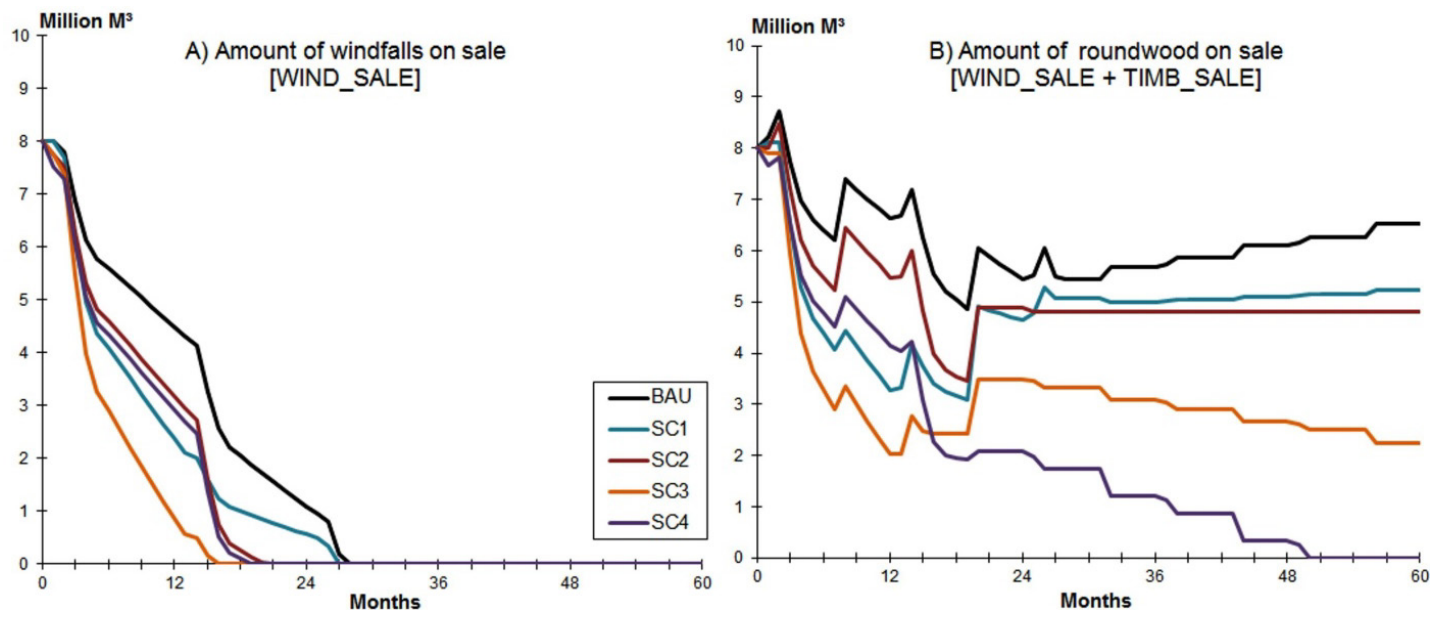

Figure 7. Levels of stocks (million $\mathrm{m}^{3}$ ) for business-as-usual (BAU) and crisis scenarios (SC1 to SC4). 
Figure 8A displays the results of the simulations for the harvesting subsystem. Predictably, strengthening harvesting capacity had a clear impact on the harvesting time. If no measure is taken, harvesting the amount of windfalls in 60 months is clearly impossible; with a $20 \%$ increase in capacity, however, the harvest time will be reduced to 45 months. Even with an increase in harvesting capacity (i.e., by investing in the acquisition of mechanical equipment), operations will last roughly three years for windfalls (SC2, SC3 and SC4). Figure 8B shows that the total roundwood stock to harvest declines to its initial level after only five years in the SC2 and SC4 scenarios.
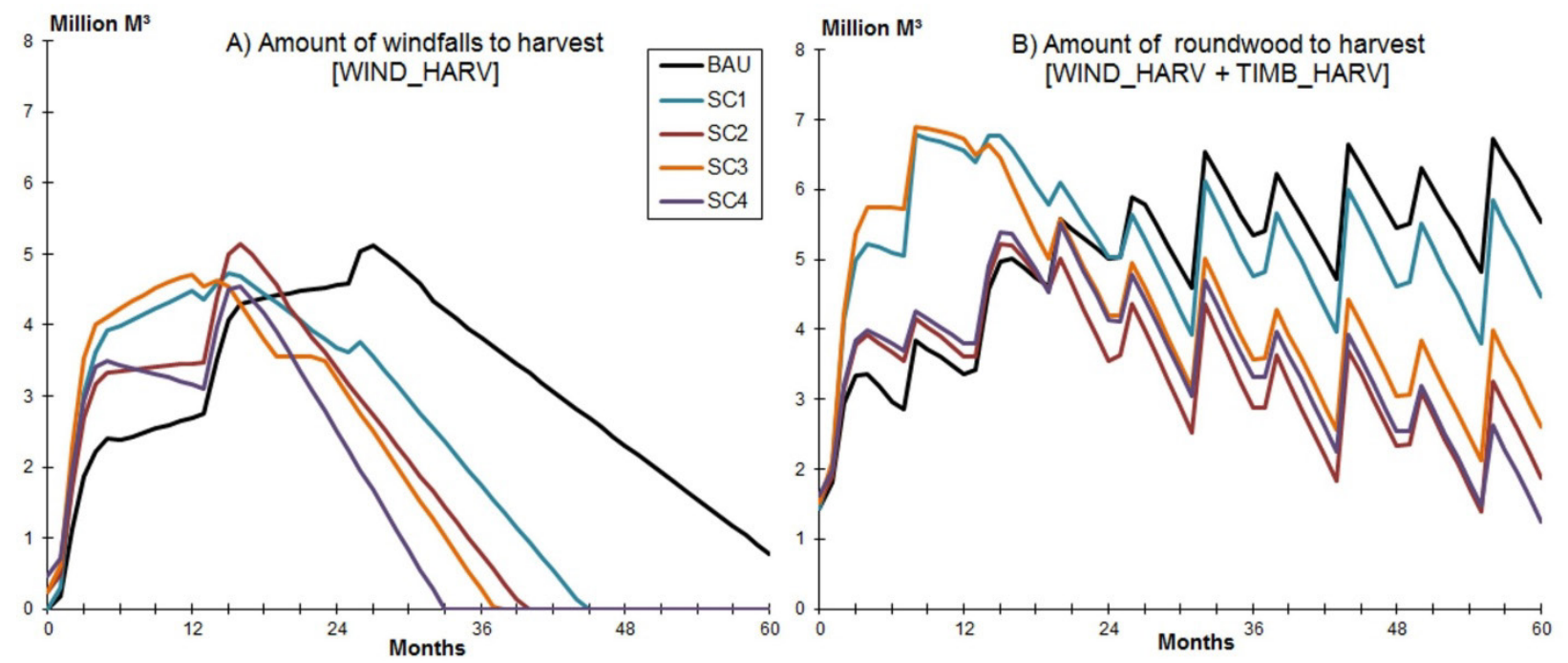

Figure 8. Levels of stocks (million $\mathrm{m}^{3}$ ) for business-as-usual (BAU) and crisis scenarios (SC1 to SC4).

Figure 9 illustrates how transport and storage crisis policies influence system behavior. The quantities of stored roundwood (exclusively windfalls) correspond to the assigned objective of 1.2 and $1.6 \times 10^{6} \mathrm{~m}^{3}$ (see Figure 9A). For SC3, 18 months are needed to reach the targeted value of the stock, while 24 months are necessary in SC4. In both cases, the volume of beech available each month is the limiting factor in filling all storage terminals. As transport capacity is optimized at that time, the removal from storage will last less time. The DSS estimates the costs of storage for water sprinkling at $€ 24$ and $€ 35$ million, respectively, for an average cost per stored cubic meter of $€ 20$ in SC3 and $€ 22$ in SC4. The need for storage policy is made quite clear when looking at the surplus stocks in industry for softwood species (see Figure 9B). Concerning softwood, wood storage contributes to reducing (SC3) or eliminating (SC4) excess deliveries relative to SC2 (at the same transport rate). 

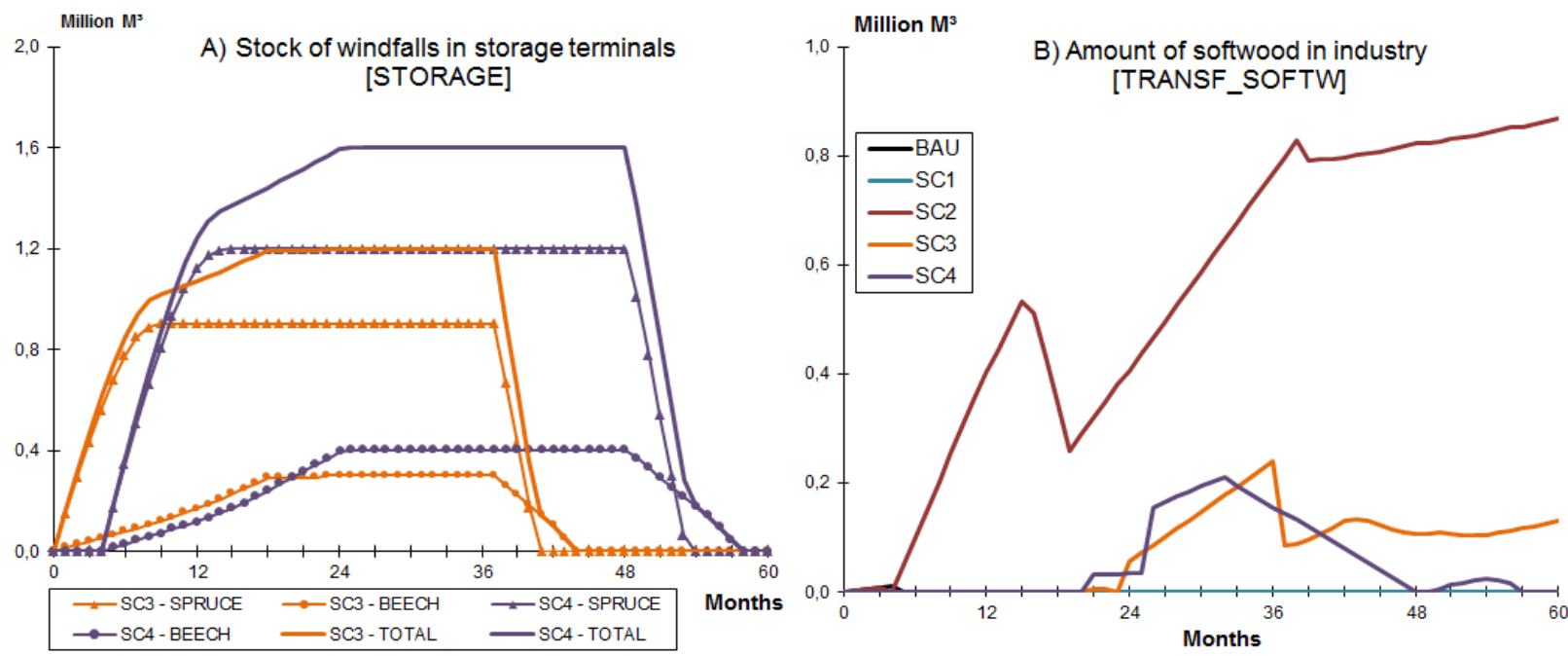

Figure 9. Levels of stocks (million $\mathrm{m}^{3}$ ) for business-as-usual (BAU) and crisis scenarios (SC1 to $\mathrm{SC} 4)$.

From a systemic point of view, all scenarios lead to a surplus of sales relative to the five-year reference value of forest sector needs. In these simulations, a $10 \%$ demand reduction does not balance a sharp decrease in stumpage prices. The first bottleneck in the wood mobilization chain appears to be the harvesting capacity (see Figure 10A). Without any strategic measure (BAU), the loss of harvesting productivity in damaged areas leads to a loss of $5 \times 10^{6} \mathrm{~m}^{3}$ at the end of the simulation period relative to the reference value. However, this objective is met when harvesters and the workforce increase by $20 \%$ (SC1 to SC4). The second bottleneck appears to be the transport of windfalls and timber products (see Figure 10B). An increase in the maximum authorized truck weight from 44 to 55 tons is enough to bring the necessary supply to industry (SC2); if the storage option is activated (SC3 and SC4), however, the transport capacity must be boosted. Transport capacity can also be improved by increasing the number of trucks. Finally, the overall industry demand for local resources (the dashed lines in Figure 10) is supplied only in SC1 and SC2, for which there are no storage operations.
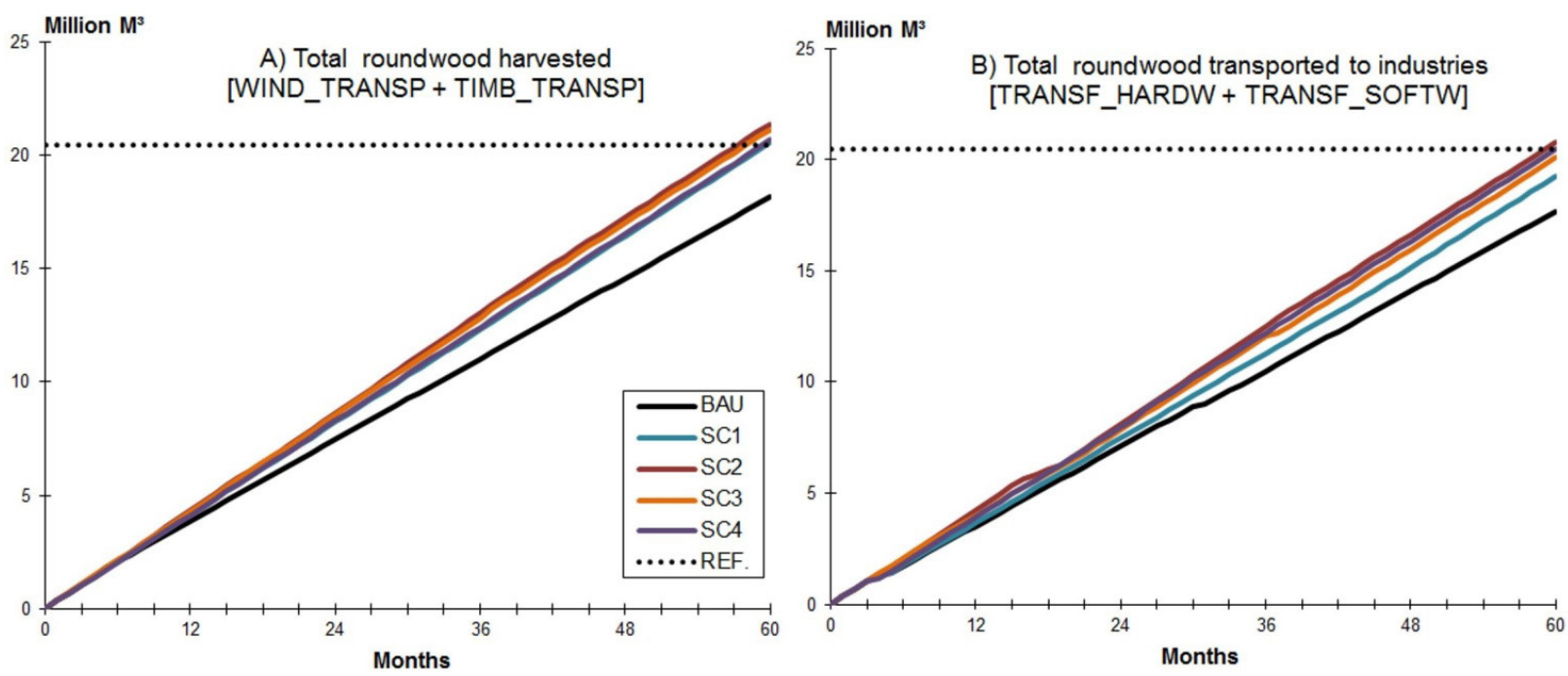

Figure 10. Roundwood (windfalls plus timber) cumulative flows (million $\mathrm{m}^{3}$ ) for business-as-usual (BAU) and crisis scenarios (SC1 to SC4). 


\section{Discussion and Conclusions}

Decision makers in storm crisis management often lack the tools for evaluating the consequences of their strategic decisions. Crisis measures that appeared efficient when considered in isolation have actually been counterproductive because the forest-based sector was not considered from a systemic point of view, indicating the need to develop a new type of DSS able to reproduce the dynamics of forest operations (e.g., sales, harvesting, transport, transformation) in a disrupted market situation. The WALFORM model developed and calibrated for the Wallonia region in Belgium serves as the basis of this DSS. Based on the system dynamics modeling approach, the WIND-STORM tool focuses on system behavior rather than numerical results [33]. The DSS, based on 61 parameters, can simulate a wide range of crisis management scenarios. A graphic user interface and advanced database management capabilities for data access, key requirements for an efficient DSS [39], have been developed.

The results of the case study presented in Chapter 3 suggest that the DSS reflects the variations among scenarios quite accurately. More generally, the DSS provides a wide spectrum of information to the end-user, allowing all types of scenario to be simulated. WIND-STORM can also be used prospectively. Simulations should be run between two crises to identify which key elements to focus on when the next calamity occurs and find structural solutions for the system bottlenecks. The DSS could be optimized by automating the simulation phase to generate a portfolio of scenarios derived from the initial level of damage and then selecting those that correspond to the decision-makers' options. However, a fully optimized process is not possible because qualitative criteria such as political, social, environmental, and ethical considerations are also part of the decision process. Though the DSS offers decision-makers a wide range of possibilities, it cannot provide the optimal scenario for storm damage management.

This paper does not pretend to identify new storm damage management options, but it can foster systemic approaches in decision-making. In this field, this study's proposed use of system thinking and methodology supported by a modeling tool is novel. Reports and analyses on storm event management [40-43] have often mentioned a lack of coordination between forest-based stakeholders and decision-makers. The joint use of a DSS in a crisis unit forces decision-makers and forest stakeholders to share opinions and to compromise, thus fostering successful crisis management.

Nevertheless, this approach has some weaknesses. The first concerns the model development and the necessity of representing the real forest-wood chain with a limited number of parameters. This need introduces minor compromises for convenience [44] and generates unexpected effects. However, sensitivity analyses conducted on selected parameters tend to confirm the robustness of the model outputs [37]. Nevertheless, model sensitivity should be further investigated to inform end-users of the expected impacts of all parameters on the system. A second drawback is the complexity of the model and the difficulty users may have understanding the mechanisms behind the results [11]. Decision-makers may not feel confident when using a DSS as a "black box" to produce policy recommendations [45], as they must explain why and how their decisions are made. According to [33], a good model is ultimately the one that is used. In other words, if decision-makers cannot follow the reasoning used by the system, they are not likely to understand its output or follow the DSS' recommendations [46]. To address this issue, stakeholders were involved in the modeling step [47], 
and training was provided to end-users afterwards. Finally, data availability and updates may be another limitation. The use of the DSS must be prepared before a crisis occurs, and the data must be continuously updated by the forest public service, the recipient of the DSS after its development. This need may interfere with the correct use of the tool during emergencies.

Despite these limitations, the DSS could be highly valuable for the forest-based sector if, and only if, the decisional context is appropriate. The search for a well-balanced solution relies on data coming from stakeholders, and false or truncated information will lead to poor decisions. More generally, sound decisions require honesty and confidence among all stakeholders, including public authorities, the forest community (e.g., scientists, practitioners), and actors in the forest-wood chain. Public authorities must keep the global welfare of the forest sector in mind because strategic decisions will be cost-efficient only if they are balanced and satisfactory for all parties. Meanwhile, the role of scientific community is to inspire confidence in the approach — as system thinking is seldom used in forestry - and address methodological concerns. In addition, while computer systems can deal with the structured portion of a problem [48], the judgment of the decision-maker is required to deal with the unstructured part [49]. Thus, decision-makers must seek advice from the forest community throughout the decision-making process. This kind of participatory process is also useful for the forest sector as a whole because sound strategies enhances the efficiency of the use of public resources [50].

Of course, this DSS is just one tool among several that could help public authorities, decision-makers, and operational managers in the aftermath of huge storms. Other critical aspects of storm damage management should be addressed in future works - damage assessment and timber storage, for instance. Damage assessment is very important because the post-storm strategy is based on it. Appropriate methods of collecting data quickly after the calamity are thus needed, as well as IT tools for facilitating data transmission and processing. A tool for supporting the tactical management of storage operations is also very important, as this paper showed that the location of storage terminals and associated transport capacity are key elements of storage policy. Using a Geographical Information System (GIS) to identify potential storage locations before the storm and ideal localizations of terminals after the event could also be very useful. From a regional point of view, Wallonia still lacks the risk assessment tools for predicting the probability of damage in forest areas and producing risk maps with which to inform decision-makers of risk levels. The risk assessment approaches used in bordering countries [51,52] should be tested and adapted to regional specifications in order to provide a fully integrated approach to wind-risk management and facilitate the transition from risk assessment to crisis management.

\section{Acknowledgements}

The General Directorate of Agriculture, Natural Resources and Environment (DGARNE) of the Public Service of Wallonia (SPW) financially supported this work. The authors wish to thank the following Belgian associations for model validation: Fédération Nationale des Scieries (FNS), Société Royale Forestière de Belgique (SRFB), Fédération Nationale des Experts Forestiers (FNEF), Union Nationale des Entreprises du Bois (UNEBO) and Département de la Nature et des Forêts (DNF). The authors also thank the two anonymous reviewers for their helpful comments. 


\section{Author Contributions}

Simon Riguelle supervised the development of the WALFORM model and the WIND-STORM DSS and was in charge of mathematical formulation and model programming. Jacques Hébert and Benoit Jourez conceptually initiated and directed the research project.

\section{Conflicts of Interest}

The authors declare no conflict of interest.

\section{References}

1. Schelhaas, M.J.; Nabuurs, G.J.; Schuck, A. Natural disturbances in the European forests in the 19th and 20th centuries. Glob. Chang. Biol. 2003, 9, 1620-1633.

2. Gardiner, B.; Blennow, K.; Carnus, J.-M.; Fleischer, M.; Ingemarson, F.; Landmann, G.; Lindner, M.; Marzano, M.; Nicoll, B.; Orazio, C.; et al. Destructive Storms in European Forests: Past and Forthcoming Impacts. Final Report to the European Commission-DG Environment; European Forest Institute: Joensuu, Finland, 2010.

3. Hanewinkel, M.; Peyron, J.-L. The economic impact of storms. In Living with Storm Damage to Forests; Gardiner, B., Schuck, A., Schelhaas, M.-J., Orazio, C., Blennow, K., Nicoll, B., Eds.; European Forest Institute: Joensuu, Finland, 2013; pp. 55-63.

4. Peyron, J.-L. Des dégâts bien difficiles à évaluer monétairement. Rev. For. Fr. 2002, 31-37, doi:10.4267/2042/4987.

5. Brunette, M.; Couture, S.; Laye, J. Optimizing Forest Production When Storms Have an Impact on Both Production and Price: A Markov Decision Process Approach; Laboratoire d'Economie Forestière: Nancy, France, 2012.

6. Prestemon, J.P.; Holmes, T.P. Market dynamics and optimal timber salvage after a natural catastrophe. For. Sci. 2004, 50, 495-511.

7. Nieuwenhuis, M.; O’Connor, E. Financial impact evaluation of catastrophic storm damage in Irish forestry: A case study. II. Future revenue losses. Forestry 2001, 74, 383-393.

8. Schwarzbauer, P.; Rauch, P. Impact on industry and markets-Roundwood prices and procurment risks. In Living with Storm Damage to Forests; Gardiner, B., Schuck, A., Schelhaas, M.-J., Orazio, C., Blennow, K., Nicoll, B., Eds.; European Forest Institute: Joensuu, Finland, 2013; pp. 64-69.

9. Packalen, T.; Marques, A.; Rasinmäki, J.; Rosset, C.; Mounir, F.; Rodriguez, L.C.E.; Nobre, S.R. Review. A brief overview of forest management decision support systems (FMDSS) listed in the FORSYS wiki. For. Syst. 2013, 22, 263-269.

10. Segura, M.; Ray, D.; Maroto, C. Decision support systems for forest management: A comparative analysis and assessment. Comput. Electron. Agric. 2014, 101, 55-67.

11. Wibe, S. A simple simulation model for the forest sector. J. For. Econ. 2005, 11, 45-52.

12. Hanewinkel, M.; Cullmann, D.A.; Schelhaas, M.J.; Nabuurs, G.J.; Zimmermann, N.E. Climate change may cause severe loss in the economic value of European forest land. Nat. Clim. Chang. 2013, 3, 203-207. 
13. Ochuodho, T.O.; Lantz, V.A. Economic impacts of climate change in the forest sector: A comparison of single-region and multiregional CGE modeling frameworks. Can. J. For. Res. 2014, 44, 449-464.

14. Sohngen, B.; Mendelsohn, R.; Sedjo, R. A global model of climate change impacts on timber markets. J. Agric. Resour. Econ. 2001, 26, 326-343.

15. Buongiorno, J.; Zhu, S.; Zhang, D.; Turner, J.; Tomberlin, D. The Global Forest Products Model; Academic Press: San Diego, CA, USA, 2003.

16. Kong, J.; Rönnqvist, M.; Frisk, M. Modeling an integrated market for sawlogs, pulpwood, and forest bioenergy. Can. J. For. Res. 2012, 42, 315-332.

17. Karlsson, J.; Rönnqvist, M.; Bergström, J. An optimization model for annual harvest planning. Can. J. For. Res. 2004, 34, 1747-1754.

18. Murphy, G.; Vanderberg, M. Modelling the economics of extended shifts and 24/7 forest harvesting. N. Z. J. For. Sci. 2007, 52, 15-19.

19. Spinelli, R.; Hartsough, B.R.; Magagnotti, N. Productivity standards for harvesters and processors in Italy. For. Prod. J. 2010, 60, 226-235.

20. Forsberg, M.; Frisk, M.; Rönnqvist, M. FlowOpt-A decision support tool for strategic and tactical transportation planning in forestry. Int. J. For. Eng. 2005, 16, 101-114.

21. Carlgren, C.G.; Carlsson, D.; Rönnqvist, M. Log sorting in forest harvest areas integrated with transportation planning using backhauling. Scand. J. For. Res. 2006, 21, 260-271.

22. Frisk, M.; Göthe-Lundgren, M.; Jörnsten, K.; Rönnqvist, M. Cost allocation in collaborative forest transportation. Eur. J. Oper. Res. 2010, 205, 448-458.

23. Weintraub, A.; Romero, C. Operations research models and the management of agricultural and forestry resources: A review and comparison. Interfaces 2006, 36, 446-457.

24. D'Amours, S.; Rönnqvist, M.; Weintraub, A. Using operational research for supply chain planning in the forest products industry. INFOR 2008, 46, 265-281.

25. Chesneau, J.B.; Le Net, E.; Berg, S. A transport tool to evaluate sustainability impacts of transport processes within the forest wood chain. Eur. J. For. Res. 2012, 131, 73-80.

26. Palander, T.; Voutilainen, J. A decision support system for optimal storing and supply of wood in a Finnish CHP plant. Renew. Energy 2013, 52, 88-94.

27. Broman, H.; Frisk, M.; Rönnqvist, M. Supply chain planning of harvest and transportation operations after the storm Gudrun. INFOR 2009, 47, 235-245.

28. Forrester, J.W. System dynamics, systems thinking, and soft OR. Syst. Dyn. Rev. 1994, 10, 245 256.

29. Bousquet, F.; le Page, C. Multi-agent simulations and ecosystem management: A review. Ecol. Model. 2004, 176, 313-332.

30. Collins, R.D.; de Neufville, R.; Claro, J.; Oliveira, T.; Pacheco, A.P. Forest fire management to avoid unintended consequences: A case study of Portugal using system dynamics. J. Environ. Manag. 2013, 130, 1-9.

31. Stern, T.; Ledl, C.; Braun, M.; Hesser, F.; Schwarzbauer, P. Biorefineries' impacts on the Austrian forest sector: A system dynamics approach. Technol. Forecast. Soc. 2015, 91, 311-326.

32. Schwarzbauer, P.; Weinfurter, S.; Stern, T.; Koch, S. Economic crises: Impacts on the forest-based sector and wood-based energy use in Austria. For. Policy Econ. 2013, 27, 13-22. 
33. Buongiorno, J. Forest sector modeling: A synthesis of econometrics, mathematical programming, and system dynamics methods. Int. J. Forecast. 1996, 12, 329-343.

34. Mentzer, J.T.; DeWitt, W.; Keebler, J.S.; Min, S.; Nix, N.W.; Smith, C.D.; Zacharia, Z.G. Defining supply chain management. J. Bus. Logist. 2001, 22, 1-25.

35. Riguelle, S.; Hébert, J.; Jourez, B. Un outil d'aide à la décision pour la gestion des chablis en Région wallonne. Innov. Agron. 2009, 6, 113-123.

36. Sanchez, C.; Hébert, J.; Rondeux, J. Analyse des prix de ventes des bois en forêts publiques. For. Wallonne 2004, 73, 30-34.

37. Kallio, A.M.I. Accounting for uncertainty in a forest sector model using Monte Carlo simulation. For. Policy Econ. 2010, 12, 9-16.

38. Jiménez-Montealegre, R.; Verdegem, M.C.J.; van Dam, A.; Verreth, J.A.J. Conceptualization and validation of a dynamic model for the simulation of nitrogen transformations and fluxes in fish ponds. Ecol. Model. 2002, 147, 123-152.

39. Muys, B.; Hynynen, J.; Palahi, M.; Lexer, M.J.; Fabrika, M.; Pretzsch, H.; Gillet, F.; Briceño, E.; Nabuurs, G.-J.; Kint, V. Simulation tools for decision support to adaptive forest management in Europe. For. Syst. 2010, 19, 86-99.

40. Mortier, F.; Bartet, J.H. Intégrons la culture de gestion de crise en milieu naturel notamment à la lumière de l'expérience des tempêtes de 1999. Rev. For. Fr. 2004, 56, 307-321.

41. Bavard, D.; de Lagarde, O.; Magrum, M. Évaluation du Volet Mobilisation des Bois ChablisPlan de Solidarité Nationale Consécutif à La Tempête Klausdu 24 Janvier 2009; Conseil général de l'alimentation; de l'agriculture et des espaces ruraux (CGAAER); Ministère de l'Agriculture; de l'Agroalimentaire et de la Forêt (MAAF): Pairs, France, 2013; p. 243.

42. Barthod, C. Les tempêtes de 1999 vues comme un révélateur du système-acteurs forestier. In $L a$ Forêt Face Aux Tempêtes; Birot, Y., Landmann, G., Bonhême, I., Eds.; Quae: Versailles, France, 2009; pp. 7-11.

43. Raetz, P. Les Enseignements de La Gestion D'une Crise. Synthèse Du Programme de Recherche Lothar; Office fédéral de l'environnement, des forêts et du paysage: Berne, Suisse, 2004; p. 84.

44. Vanclay, J. Unsuspected implications arising from assumptions in simulations: Insights from recasting a forest growth model in system dynamics. For. Ecosyst. 2014, 1, 1-10.

45. Reynolds, K.; Twery, M.; Lexer, M.J.; Vacik, H.; Ray, D.; Shao, G.; Borges, J.G. Decision support systems in natural resource management. In Handbook on Decision Support Systems; Burnstein, F., Holsapple, C., Eds.; Springer: Berlin, Germany; Heidelberg, Germany, 2008; Volume 2, pp. 499-534.

46. Garcia-Gonzalo, J.; Palma, J.; Freire, J.; Tomé, M.; Mateus, R.; Rodriguez, L.C.E.; Bushenkov, V.; Borges, J.G. A decision support system for a multi stakeholder's decision process in a Portuguese National Forest. For. Syst. 2013, 22, 359-373.

47. Voinov, A.; Bousquet, F. Modelling with stakeholders. Environ. Model. Softw. 2010, 25, 1268-1281.

48. Hujala, T.; Khadka, C.; Wolfslehner, B.; Vacik, H. Review. Supporting problem structuring with computer-based tools in participatory forest planning. For. Syst. 2013, 22, 270-281.

49. Shim, J.P.; Warkentin, M.; Courtney, J.F.; Power, D.J.; Sharda, R.; Carlsson, C. Past, present, and future of decision support technology. Decis. Support Syst. 2002, 33, 111-126. 
50. Tuomasjukka, D.; Lindner, M.; Edwards, D. A concept for testing decision support tools in participatory processes applied to the ToSIA tool. Challenges 2013, 4, 34-55.

51. Gardiner, B.; Byrne, K.; Hale, S.; Kamimura, K.; Mitchell, S.J.; Peltola, H.; Ruel, J.C. A review of mechanistic modelling of wind damage risk to forests. Forestry 2008, 81, 447-463.

52. Hanewinkel, M.; Hummel, S.; Albrecht, A. Assessing natural hazards in forestry for risk management: A review. Eur. J. For. Res. 2011, 130, 329-351.

(C) 2015 by the authors; licensee MDPI, Basel, Switzerland. This article is an open access article distributed under the terms and conditions of the Creative Commons Attribution license (http://creativecommons.org/licenses/by/4.0/). 